\title{
Influence of High-Density electropulsing treatment on the interface corrosion characteristics of 316L steel in Lead-Bismuth eutectic at $823 \mathrm{~K}$
}

\author{
Shujian Tian ${ }^{1}$, Jianwu Zhang ${ }^{2 *}$, Yuying Wang ${ }^{1}$, Yiyi Ma ${ }^{1}$, and Weishu Wang ${ }^{1}$ \\ ${ }^{1}$ School of Electric Power, North China University of Water Resources and Electric Power, Zhengzhou 450045, China \\ ${ }^{2}$ Department of Physics, University of Science and Technology of China, Hefei 230026, China
}

\begin{abstract}
In order to find an effective method to improve the corrosion resistance properties of the candidate structural materials for lead-alloy cooled fast reactors, the $316 \mathrm{~L}$ steel was treated by high density single electropulsing. And then the interface corrosion characteristics in stagnant lead-bismuth eutectic (LBE) at $823 \mathrm{~K}$ for $1000 \mathrm{~h}$ were examined. The results show that electropulsing treatment (EPT) has a significant influence on microcosmic appearance and corrosion depth of the corroded specimens. All the specimens were subjected to dissolution corrosion, but EPT with a current density of $1828 \mathrm{~A} \mathrm{~mm}^{-2}$ can improve obviously the corrosion resistance and reduce the extent of local corrosion of 316L in LBE. In addition, the corrosion depth of the $1828 \mathrm{~A} \mathrm{~mm}^{-2}$ EPT specimen decreases by $38 \%$, compared with that of the non-EPT specimens.
\end{abstract}

\section{Introduction}

Lead-bismuth eutectic (LBE), due to its excellent thermalphysical properties and high neutron economy, is one of the candidate coolants and spallation target materials for application in lead-alloy cooled fast reactors (LFR) and accelerator driven systems (ADS) [1]. However, one of the main issues is the compatibility of the candidate structural materials with LBE, which is one of the lifetime-determining factors for the reactor components, due to the dissolution of steel constituents into LBE at elevated temperatures [2]. In order to inhibit corrosion from LBE and prolong the service life of structural materials, it is necessary to develop some effective methods to improve the corrosion resistance of structural materials.

One promising method to reduce the corrosion rate is the addition of elements (for example $\mathrm{Zr}$, Ti or $\mathrm{O}$ ) in a proper concentration that inhibit corrosion by forming a protective film [3]. Recently, a special anti-corrosion treatment, called GESA, has been developed. GESA uses a very intense electrons beam to merge the steel at the surface with a protective layer $(\mathrm{FeCrAl})$ applied by the LPPS (Low Pressure Plasma Spraying) technique [4]. In recent years, electropulsing treatment (EPT) has been received much attention due to the special properties it imparts to the treated materials $[5,6]$. Previous studies have indicated that an electric current can significantly affect material behaviors such as electromigration, electroplasticity, metal and alloy solidification, amorphous solid structural relaxation, and amorphous crystallization [7-13]. Liu et al. studied effect of EPT on corrosion behavior of nickel base corrosion-resistant alloy [14]. They found that the intergranular corrosion resistance could be improved substantially without the degradation of tensile properties of the alloy by EPT. Therefore, EPT is attempted to improve the corrosion resistance of the steel matrix in LBE in present work.

The austenitic stainless steel $316 \mathrm{~L}$ is a widely used engineering material which has the good formability and excellent resistance against corrosion and oxidation [15]. Even so, when exposed to the liquid LBE with dissolved oxygen, the $316 \mathrm{~L}$ steel is corroded. In present work, the 316L steel was treated with high-density electropulsing to investigate how EPT affects corrosion resistance in stagnant $\mathrm{LBE}$ at $823 \mathrm{~K}$ for $1000 \mathrm{~h}$.

\section{Experimental}

\subsection{Materials and EPT Condition}

The chemical compositions of the investigated steel 316L are given in Table 1 . The $316 \mathrm{~L}$ was annealed in air at 1323 $\mathrm{K}$ for $30 \mathrm{~min}$, and then cooled down to room temperature in water. Subsequently, the $316 \mathrm{~L}$ was machined along the rolling direction to produce a set of thin specimens with dimensions of $70 \mathrm{~mm} \times 4.2 \mathrm{~mm} \times 1.2 \mathrm{~mm}$. Before the corrosion test, the specimens were ground using $\mathrm{SiC}$ paper up to $\# 600$, and then were washed in acetone and ultrasonically cleaned in an acetone bath.

\footnotetext{
*Corresponding author: tiansj@mail.ustc.edu.cn
} 
Table 1. Chemical compositions of the investigated 316L steel (wt. \%).

\begin{tabular}{|c|c|c|c|c|c|c|c|c|}
\hline Material & $\mathrm{C}$ & $\mathrm{Cr}$ & $\mathrm{Ni}$ & Mo & $\mathrm{Mn}$ & $\mathrm{V} \mathrm{Nb}$ & $\mathrm{Si}$ & $\mathrm{Fe}$ \\
\hline $316 \mathrm{~L}$ & $\leq 0.03$ & 17.31 & 10.67 & 2.47 & 1.47 & $-\quad-$ & 0.65 & Bal \\
\hline
\end{tabular}

The experimental setup for the EPT and the typical electropulsing waveform are shown in Figure 1 [13]. As shown in Figure 1a, the two ends of each specimen were connected to a discharge circuit through copper electrodes during EPT. The capacitor banks were then discharged to electropulse the specimen in air as follows. A trigger circuit was used to discharge the capacitor banks though the specimen to achieve high-density electropulsing. The waveform of electropulsing was detected to be a damped oscillation wave via a Rogowski coil and a TDS3012 digital storage oscilloscope, as shown in Figure 1b. Although the electropulse waveforms were similar, the maximum current densities $(\mathrm{J} \mathrm{m})$ of EPT were different due to the different load voltage. The pulse duration (about $800 \mu \mathrm{s}$ ) and the electropulse period $(\mathrm{tp}=110 \mu \mathrm{s})$ were almost identical for different waveforms. Each specimen was treated only once by the high-current-density electropulsing.

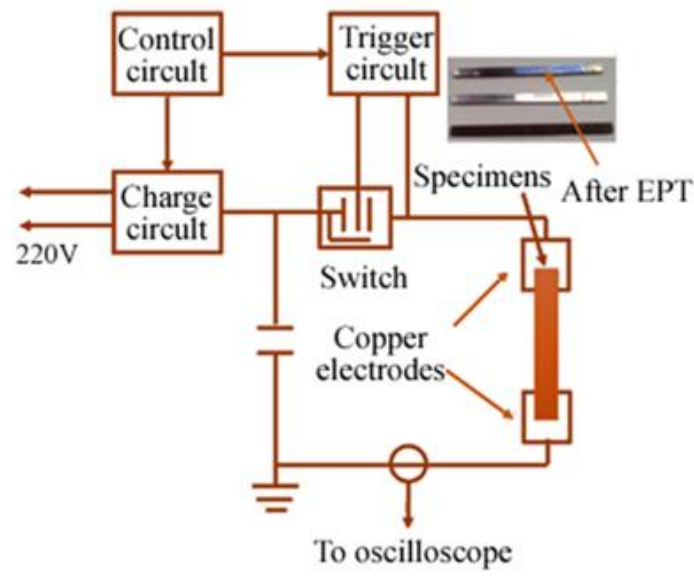

(a)

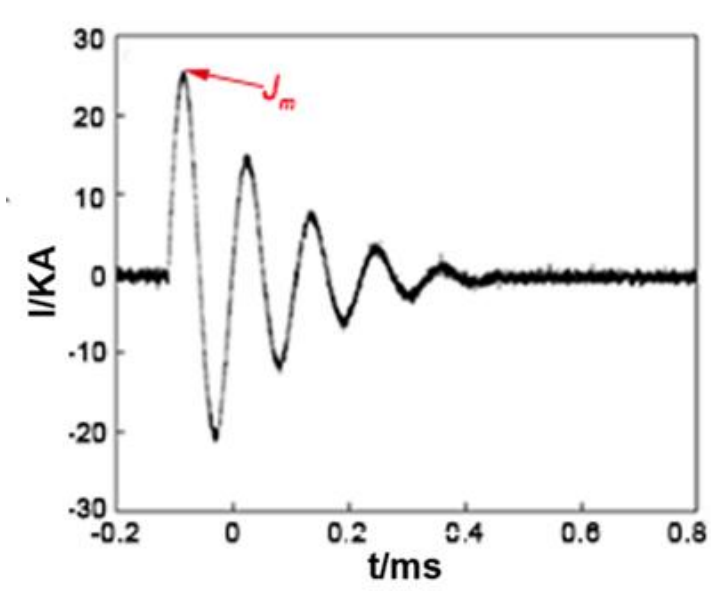

(b)

Figure. 1. The schematic diagram of the experimental setup for the EPT and the typical electropulsing waveform: (a) The schematic diagram of the experimental setup and (b) the typical electropulsing waveform.

The EPT conditions used for the corrosion-test specimens are listed in Table 2. After EPT, each of the corrosion-test specimens above-mentioned was cut into several small specimens with dimensions of $10 \mathrm{~mm} \times 4.2 \mathrm{~mm} \times 1.2$ $\mathrm{mm}$. As shown in Table 2, these small specimens were divided into six groups (L, A, B, C, D and E) depending on the different current densities, and each group consisted of three specimens with identical treatment. The group-L specimens, which were not electropulsed, were used as references.

Table 2. The EPT conditions used for the corrosion-test specimens.

\begin{tabular}{ccccccc}
\hline Group & $\mathrm{L}$ & $\mathrm{A}$ & $\mathrm{B}$ & $\mathrm{C}$ & $\mathrm{D}$ & $\mathrm{E}$ \\
\hline $\begin{array}{c}J_{m} \\
\left(\mathrm{~A} / \mathrm{mm}^{2}\right)\end{array}$ & 0 & 1828 & 2828 & 3902 & 4692 & 5841 \\
$\mathrm{U}(\mathrm{V})$ & 0 & 3000 & 5100 & 6900 & 8100 & 9600 \\
$\tau_{p}(\mu \mathrm{s})$ & 0 & 800 & 800 & 800 & 800 & 800 \\
$t_{p}(\mu \mathrm{s})$ & 0 & 110 & 110 & 110 & 110 & 110 \\
\hline
\end{tabular}

Note: $\mathrm{Jm}$ is the amplitude of current density of electropulsing. U is the charging voltage of the capacitor banks. $\tau p$ is the pulse duration for the electropulsing waveforms. tp is the electropulse period for the electropulsing waveforms.

\subsection{Corrosion Test and Examination of Corro- sion Effects}

The surfaces of the electropulsed corrosion-test specimens were ground using $\mathrm{SiC}$ paper up to \#2000 and were then polished to a 1.5- $\mu \mathrm{m}$ finish. The polished specimens were subsequently washed in acetone and ultrasonically cleaned in an acetone bath. The specimens in the identical group were placed in the identical Mo crucible (Figure 2). LBE was placed in an alumina crucible in a glove box and melted at $473 \mathrm{~K}$ under Hi-purity Argon (99.999\%) atmosphere. After the LBE was melted, the resulting dross of floating oxides and other impurities were carefully 
removed with stainless steel spoon. Each Mo crucible was filled with the melted LBE afterwards. In order to prevent the specimens from floating above the LBE, Molybdenum mesh was used and fixed in the middle of the Mo crucible. After cooling down to room temperature, Mo crucibles were taken out from the glove box and put into a stainless steel container (Figure 2). The stainless steel container was highly evacuated and then filled with

Hi-purity Argon (99.999\%) achieving a small pressure to prevent the LBE from excessive oxidation. Then it was heated by an electric strip heater and kept the internal temperature in the container of $823 \mathrm{~K}$ for $1000 \mathrm{~h}$. It should be noted, $823 \mathrm{~K}$ is the maximum temperature in the typical operating temperature range $(623 \mathrm{~K}-823 \mathrm{~K})$ for the LBE cooled reactor. In the process of LBE operation and corrosion, the LBE was in the Hi-purity Argon protection environment all the time. All the specimens were exposed to the same corrosion test conditions at the same time.

After the corrosion test, the uncleaned corroded specimens were embedded in epoxy resin adhesive and polished to a $1.5-\mu \mathrm{m}$ finish to examine the cross sections with backscattered electron (BSE) imaging. The chemical compositions of the adherent corrosion product and bulk material were analyzed using energy-dispersive X-ray spectroscopy (EDS).

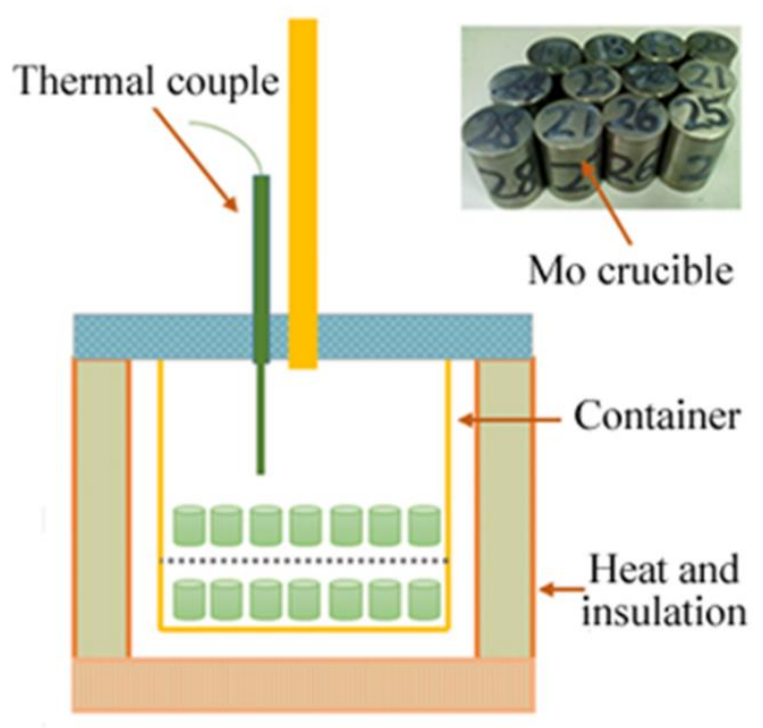

Figure 2. The schematic diagram of corrosion test setup.

\section{Results and Discussion}

\subsection{Microcosmic Appearance of Corrosion Prod- ucts}

The BSE images of the polished cross-sections of $316 \mathrm{~L}$ specimen are shown in Figure 3. Based on these images, all specimens show severe corrosion. No oxide scale is found on the surface of each specimen, and a large amount of LBE penetrates into the steel matrix. Meanwhile, a great number of steel matrix particles are also found at the LBE region. Thus, in our experimental environment, the LBE and the steel matrix interpenetrate with each other, and the LBE attacked the steel with dissolving a significant amount of steel matrix elements. In analyzing the data from the BSE images, the corrosion behavior of Group-L, $\mathrm{B}-\mathrm{E}$ are very similar, these specimens all present a local corrosion. However, as for Group-A, the corrosion behavior can be characterized by uniform corrosion. These phenomena can be justified by the BSE images in Figure 4 which is displaced in a larger scale. From Figure 4, the interfaces between LBE and the steel matrix of the specimen from Group-A are very flat, indicating that uniform corrosion happens on the Group-A specimens. With regard to the Group-L-1 and the Group-B-1, the interfaces between $\mathrm{LBE}$ and the steel matrix are rather roughness, indicating that the steel matrix is subjected to local corrosion. Thus the specimen with EPT at current density of $1828 \mathrm{~A} \mathrm{~mm}^{-2}$ has a flat corrosion cross-section morphology when exposed to stagnant LBE.

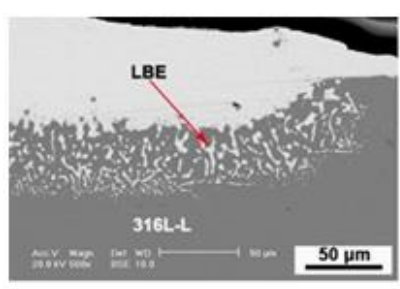

(a)

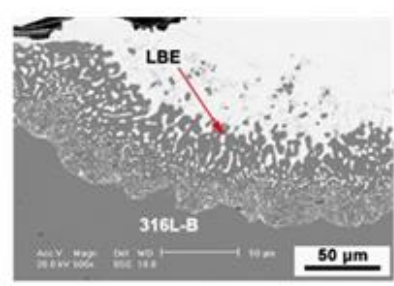

(c)

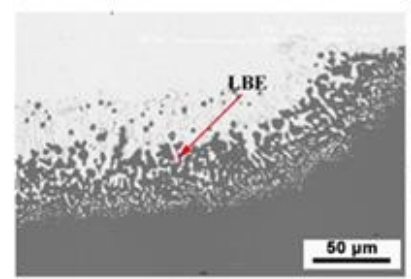

(e)

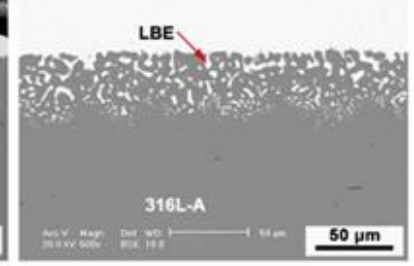

(b)

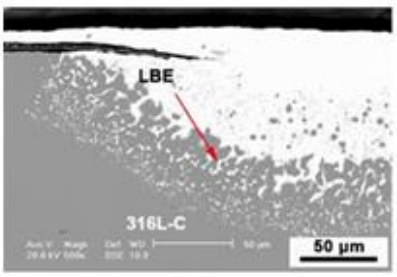

(d)

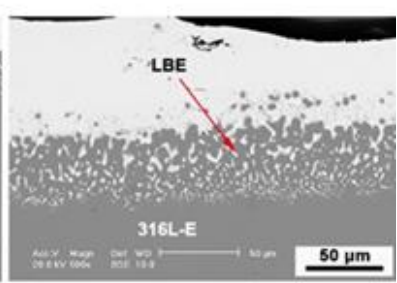

(f)
Figure.3.BSE images of polished cross sections of 316L specimens that were electropulsed at different current densities after the corrosion test at $823 \mathrm{~K}$ : (a) $J_{\mathrm{m}}=0$ for the group-L reference specimen; (b) $J_{\mathrm{m}}=1828 \mathrm{~A} \mathrm{~mm}^{-2}$ for the group-A specimen; (c) $J_{\mathrm{m}}=2828 \mathrm{~A} \mathrm{~mm}^{-2}$ for the group-B specimen; (d) $J_{\mathrm{m}}=4692 \mathrm{~A}$ $\mathrm{mm}^{-2}$ for the group-D specimen; (f) $J_{\mathrm{m}}=5841 \mathrm{~A} \mathrm{~mm}^{-2}$ for the group-E specimen. 


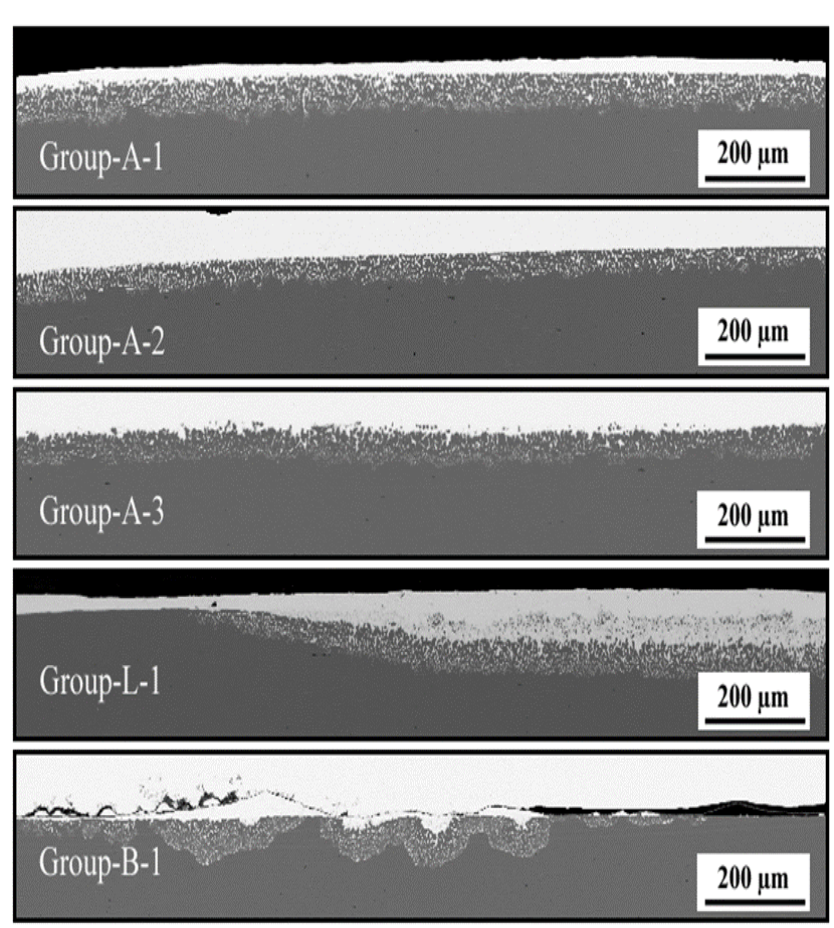

Figure.4. The BSE images of polished cross sections of the specimens in a larger scale of BSE.

\subsection{Corrosion Depth Measurement}

Corrosion depth is an important parameter in evaluating the corrosion resistance of the material exposed to the LBE. Here, the corrosion depth was the $\mathrm{Pb}$ and $\mathrm{Bi}$ penetration depth measured in BSE images. Based on these depths, the maximum corrosion depth is collected for each specimen tested in stagnant LBE at $823 \mathrm{~K}$ for $1000 \mathrm{~h}$. Then the average corrosion depth was calculated as the average of the maximum corrosion depths of three independent specimens in the same group. Figure 5 shows the corrosion depths of the $316 \mathrm{~L}$ specimen electropulsed at different current densities. The average corrosion depths for Groups-L, $\mathrm{A}, \mathrm{B}, \mathrm{C}, \mathrm{D}$ and $\mathrm{E}$ are $94 \mu \mathrm{m}, 58 \mu \mathrm{m}, 107 \mu \mathrm{m}, 95 \mu \mathrm{m}, 98$ $\mu \mathrm{m}$ and $85 \mu \mathrm{m}$, respectively. Clearly, the Group-A specimens have a better corrosion resistance than the others. As can be seen from Figure 4 and Figure 5, EPT is an effective method to influent the interface corrosion characteristics of 316L steel in LBE. This is because EPT is a rapid heating process and the energy provided by such an external source is converted into Joule heating. The resulting transient thermal stress would form a mass of supersaturated point defects, which can increase the vacancy density. Thus, the vacancies could diffuse, which would be beneficial to the diffusion of atoms. Consequently, the diffusion rate at the alloying elements interface would be higher than that in the steel matrix.

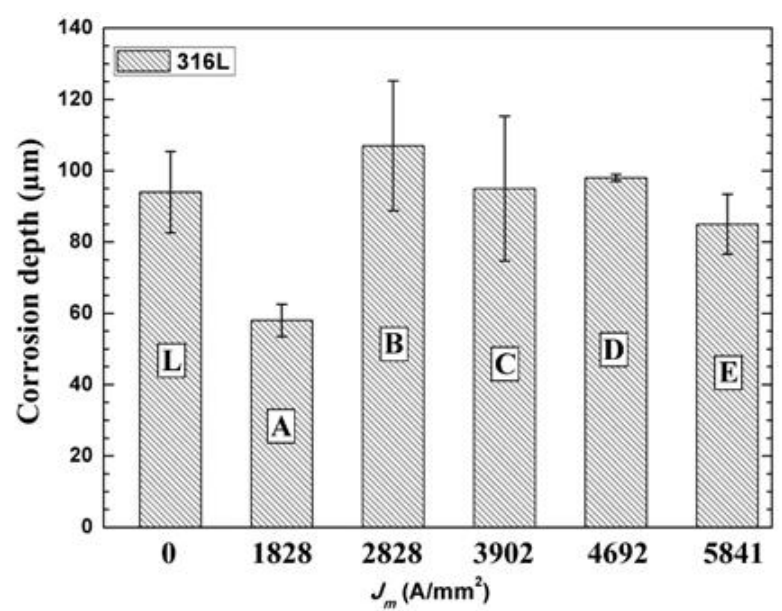

Figure.5.EPT conditions used and corrosion depths of the specimens subjected to EPT at different current densities.

\subsection{Interactions of $\mathrm{Pb}, \mathrm{Bi}$ and The Steel Matrix}

Figure 6 shows the results of the EDS mapping analysis of the group-A specimens after exposure in LBE for $1000 \mathrm{~h}$. The figure reveals the depletion of $\mathrm{Cr}$ and $\mathrm{Ni}$ near the steel surface into $\mathrm{LBE}$ and the penetration of $\mathrm{Pb}$ and $\mathrm{Bi}$ into the steel matrix. In addition, the austenite-ferrite phase transition exists in the interaction region between the steel matrix and LBE because Ni preferentially dissolves from the matrix into the LBE. The EDS map analysis indicates that EPT does not affect the dissolution process or elemental redistribution relative to the $\mathrm{L}$ specimens that were not electropulsed.

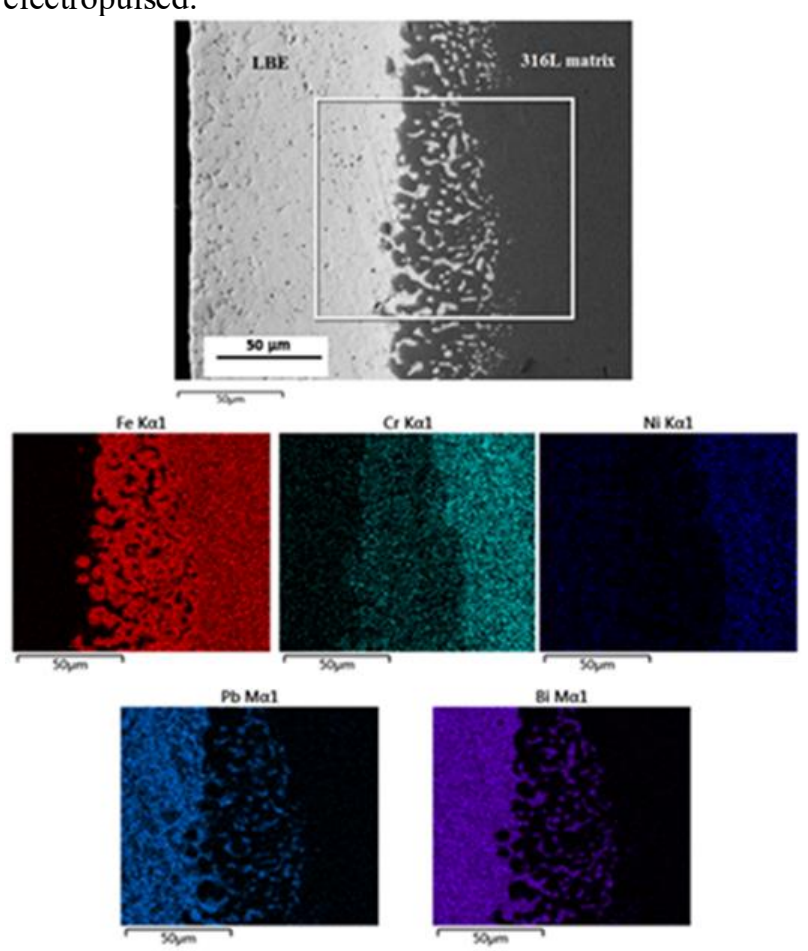

Figure.6.EDS map analysis of the group-A specimen after exposure in LBE for $1000 \mathrm{~h}$. 


\section{Conclusions}

The $316 \mathrm{~L}$ steel was treated by high density single electropulsing, and the influence of EPT on the interface corrosion characteristics in stagnant LBE at $823 \mathrm{~K}$ for $1000 \mathrm{~h}$ was investigated. The findings of the present study can be summarized as follows:

- All the 316L specimens were subjected to dissolution corrosion in stagnant LBE at $823 \mathrm{~K}$ for $1000 \mathrm{~h}$. However, EPT has a significant influence on microcosmic appearance and corrosion depth of the corroded specimens.

- The average corrosion depth of the $1828 \mathrm{~A} \mathrm{~mm}^{-2} \mathrm{EPT}$ specimen decreases by $38 \%$, compared with that of the non-EPT specimens. EPT with a current density of $1828 \mathrm{~A}$ $\mathrm{mm}^{-2}$ can improve obviously the corrosion resistance and reduce the extent of local corrosion of $316 \mathrm{~L}$ in LBE.

- EPT does not affect the dissolution process or elemental redistribution. After EPT, the depletion of $\mathrm{Cr}$ and $\mathrm{Ni}$ and the penetration of $\mathrm{Pb}$ and $\mathrm{Bi}$ still occur in the interaction region between the steel matrix and LBE.

\section{Acknowledgement}

This work was supported by the Henan Province Key Specialized Research and Development Breakthrough Program in China (No. 192102210238) and the Scientific Research Project of High-Level Talents of North China University of Water Resources and Electric Power (No. 201705011). The author would like to express sincere thanks to the members of the FDS team for their contributions to the corrosion-testing device.

\section{References}

1. Hojna, A., Hadraba, H., Gabriele, F. D., \& Husak, R.. Behaviour of pre-stressed T91 and ODS steels exposed to liquid lead-bismuth eutectic. Corrosion Science, 131, 264-277(2018).

2. Zhang, J., \& Li, N.. Review of the studies on fundamental issues in lbe corrosion 2 . Journal of Nuclear Materials, 373(1), 351-377(2008).

3. Fazio, C., Sobolev, V. P., Aerts, A., Gavrilov, S., Lambrinou, K., Schuurmans, P., ... \& Gosse, S.. Handbook on lead-bismuth eutectic alloy and lead properties, materials compatibility, thermal-hydrau -lics and technologies-2015 edition (No. NEA--72 68). Organisation for Economic Co-Operation and
Development(2015).

4. Del Giacco, M.. Investigation of Fretting Wear of Cladding Materials in Liquid Lead (Vol. 3). KIT Scientific Publishing(2013).

5. Zhou, Y., Zhang, W., Wang, B., \& Guo, J.. Ultrafinegrained microstructure in a $\mathrm{Cu}-\mathrm{Zn}$ alloy produced by electropulsing treatment. Journal of materials research, 18(8), 1991-1997(2003).

6. Zhang, W., Zhao, W. S., Li, D. X., \& Sui, M. L.. Martensitic transformation from $\alpha$-Ti to $\beta$-Ti on rapid heating. Applied physics letters, 84(24), 48724874(2004).

7. Bosvieux, C., \& Friedel, J.. Sur l'electrolyse des alliages metalliques. Journal of Physics and Chemistry of Solids, 23(1-2), 123-136(1962).

8. Ho, P. S., \& Kwok, T.. Electromigration in metals. Reports on Progress in Physics, 52(3), 301(1989).

9. Sprecher, A. F., Mannan, S. L., \& Conrad, H.. Overview no. 49: On the mechanisms for the electroplastic effect in metals. Acta Metallurgica, 34(7), 11451162(1986).

10. Misra, A. K.. A novel solidification technique of metals and alloys: under the influence of applied potential Metallurgical and Materials Transactions A, 16(7), 1354-1355(1985)..

11. Mizubayashi, H., \& Okuda, S.. Structural relaxation induced by passing electric current in amorphous $\mathrm{Cu}$ 50 Ti 50 at low temperatures. Physical Review B, 40(11), 8057(1989).

12. Lai, Z. H., Conrad, H., Teng, G. Q., \& Chao, Y. S.. Nanocrystallization of amorphous Fe-Si-B alloys using high current density electropulsing. Materials Science and Engineering: A, 287(2), 238-247(2000).

13. Hui, S. O. N. G., \& WANG, Z. J.. Grain refinement by means of phase transformation and recrystallization induced by electropulsing. Transactions of Nonferrous Metals Society of China, 21, s353-s357(2011).

14. Yang, L. I. U., Lei, W. A. N. G., Liu, H. Y., Zhang, B. J., \& Zhao, G. P.. Effect of electropulsing treatment on corrosion behavior of nickel base corrosion-resistant alloy. Transactions of Nonferrous Metals Society of China, 21(9), 1970-1975(2011).

15. Chen, X. H., Lu, J., Lu, L., \& Lu, K.. Tensile properties of a nanocrystalline $316 \mathrm{~L}$ austenitic stainless steel. Scripta Materialia, 52(10), 1039-1044 (2005). 